\title{
Analysis of Earthquake Monitoring Capability of Level Cross-fault Sites in Fujian and Jiangxi
}

\author{
Zhibin Lin ${ }^{1 a}$, Yuanrong $\mathrm{He}^{2 \mathrm{~b}}$, Changxian Zhou $^{3 \mathrm{c}}$, Hui Zhan ${ }^{3 \mathrm{~d}}$, Guangming Li ${ }^{3 \mathrm{e}}$ \\ ${ }^{1}$ Survey \& Mapping Institute,Xiamen Seismic \& Research Center,Xiamen, China \\ ${ }^{2}$ Institute of computer and information engineering, Xiamen University of Technology, Xiamen, \\ China \\ ${ }^{3}$ Survey \& Mapping Institute,Xiamen Seismic \& Research Center,Xiamen, China \\ a51434848@qq.com, bheyuanrong@126.com, ${ }^{\mathrm{c}} 41500619 @ q q . c o m,{ }^{\mathrm{d}} 275873637 @ q q . c o m,{ }^{\mathrm{e}} 159$ \\ 2495150@qq.com
}

\begin{abstract}
Keywords: Fujian and Jiangx, Cross-fault level, Earthquake, Finite element method
\end{abstract}
\begin{abstract}
This paper has a research basis on the leveling data of 5 years from 2008 to 2012 in cross-fault grounds of Fujian and Jiangxi province, by means of establishing three-dimensional finite element model to calculate the level of observed changes across the fault when the fault dip angle and the fault strike are not at the same time, and with five earthquake instances in Fujian and Jiangxi and the surrounding area from 2008 to 2012 to verify the reliability of its models. Then this paper integrated finite element model and the conclusion of five earthquakes to conduct a preliminary evaluation grading of 24 level observation areas in Fujian and Jiangxi. The results show that Fujian and Jiangxi cross-fault monitoring system has a strong level of seismic monitoring capability, when judging fault changes, it requires a combination of different ground level changes. At the same time, the factors influencing the monitoring ability of cross-fault level site are mainly fault dip Angle and the fault strike, especially when the dip Angle of fault is at $30^{\circ}$ to $80^{\circ}$ and the fault strike and horizontal ground are vertical, the reflecting ability of earthquake is the strongest.
\end{abstract}

\section{Introduction}

Fujian and Jiangxi which is located in southern China is one of the areas of new tectonic movement that occurred more frequently, and is the focus of an earthquake surveillance and protection zone, it belongs to the "to go along the southeast coast seismic belt" of "southern China earthquake zone".

Cross-fault vertical displacement measurement is one of the most direct observation means of studying crustal movement, it plays an important role in capturing earthquake precursor anomalies and the prediction of seismic risk (Din et al.,1999). Earthquake cases show that before some strong earthquakes happen, the epicenter distance within a range of cross-fault deformation monitors a more significant abnormal change (Bao et al., 2000; Zhang et al., 2007; Chen et al., 2002). Such as: before an earthquake of magnitude 7.0 happened in Lijiang City, Yunnan Province in 1996, the standard measurement of Yongsheng fault occurred a more ${ }^{1}$ significant abnormal change, mainly in the short leveling and short baseline measurements(Su et al., 2012); after an earthquake of magnitude 8.0 occurred in Wenchuan County, Sichuan Province in 2008, leveling of Xianshuihe fault zone has also undergone a more significant abnormal change(Han et al., 2004).

Earthquake cass show that under the stress of the local stress field, cross-fault grounds on the same structure of different fault blocks exist a big difference in the ability to reflect the shock of the same earthquake, and the reasons for these differences are likely to be due to the different fault dip Angle and orientation (Chen et al., 2002). Therefore, this paper collected cross-fault leveling data of Fujian and Jiangxi from 2008 to 2012, and analyzed this data, it also evaluated the regional cross-fault deformation monitoring capability and studied the factors of cross-fault leveling data discrepancies, this paper will provide the necessary reference in reducing the existing observation sites or laying the new cross-fault observation sites in the future. 
This article chooses 24 level observation areas of Fujian and Jiangxi as the research object, its purpose is to conduct a preliminary analysis of monitoring capabilities of cross-fault level sites in Fujian and Jiangxi, as shown in Table 1.

As can be seen from Table 1, Fujian and Jiangxi cross-fault level observation sites are distributed more evenly and they distribute within the various regions of Fujian. Most of the standard observation sites of faults trending are north-east and north-west; there are also some observation sites are north-south direction, while the observation site of Liuxia is east-west direction. Fault dip concentrated in $55^{\circ} \sim 80^{\circ}$, as well as some observation site fault dips are greater than $80^{\circ}$. Among Table 1 , faults dip of Dabeihuan is unknown.

Table 1 Fujian and Jiangxi level measuring point and statistics of fracture occurrence

\begin{tabular}{|c|c|c|c|c|}
\hline \multirow{2}{*}{ Number } & \multirow{2}{*}{ Observing names } & \multirow{2}{*}{ Observing fault names } & \multicolumn{2}{|c|}{ Fault occurrence } \\
\hline & & & Fault strike & Fault $\operatorname{dip}\left({ }^{\circ}\right)$ \\
\hline 1 & Cannei town in Anxi county & Yongan-Jinjiang fracture & North-west & 65 \\
\hline 2 & Dongzhang town in Fuqing city. & Dongzhang fracture & North-east & 80 \\
\hline 3 & Guikou villiage in Yongan city & Yongan-Guikou fracture & North-east & $60-70$ \\
\hline 4 & Hexi town in Nanjing county & Zhenghe-Haifeng fracture & North-east & 76 \\
\hline 5 & Nankeng village in Minhou county & Minjiang fracture & North-west & 70 \\
\hline 6 & Liuxia village in Zhangpu county & Baizhu lake fracture & East-west & 70 \\
\hline 7 & Meiling village in Huian county & Huian-lingtou fracture & South-east & 75 \\
\hline 8 & Nanshan village in Pinghe county & Shanghang-Yunxiao fracture & North-west & 70 \\
\hline 9 & Putian city & Putian-Nanri island fracture & North-west & $75-85$ \\
\hline 10 & Qianlou town in Dongshan county & Kengbei-Qianwu fracture & North-east & 56 \\
\hline 11 & Rongqing in Shishi city & Luoshangshan fracture & North-east & $57-90$ \\
\hline 12 & Sanshan town in Fuqing & Luoshangshan fracture & North-east & $57-90$ \\
\hline 13 & Shizishan in Taining county & Shaowu-Heyuan fracture & North-east & $40-70$ \\
\hline 14 & Wangjian village in Datian county & Zhenghe- Haifeng fracture & North-east & $70-85$ \\
\hline 15 & Yushan town in Jianou county & Yushan fracture & South-north & 50 \\
\hline 16 & Xiexi village & Xiexi fracture & North-east & 80 \\
\hline 17 & Huangtian & Huangtian fracture & South-north & 65 \\
\hline 18 & Wankou & Wankou fracture & North-east & 80 \\
\hline 19 & Xiguazhou & Xiguazhou fracture & North-east & 70 \\
\hline 20 & Xitang & Xitang fracture & South-north & unknown \\
\hline 21 & Dongdu & Dongdu fracture & North-east & 60 \\
\hline 22 & Dabeihuan & Dabeihuan fracture & Tendency is unknown & unknown \\
\hline 23 & Huzaishan & Huzaishan fracture & North-west & 63 \\
\hline 24 & Xiefang & Xiefang -Youshui fracture & North-east & 50 \\
\hline
\end{tabular}

\section{Model design}

Level measurement data analysis of Fujian and Jiangxi cross-fault from 2008 to 2012 is divided into the following five steps:

1) Each field measurement data of 15 periods within 5 years will be gained with the analysis of leveling measurement data from 2008 to 2012 in Fujian and Jiangxi.

2) According to the classification situation of crust in Fujian and Jiangxi to design three-dimensional nonlinear finite element models with different fault dips and fault strike.

3) According to the conclusion of three-dimensional nonlinear finite element models, the preliminary evaluation of classification of t 24 observation sites in Fujian and Jiangxi will be made. 
4) Select 5 typical earthquakes from 2008 to 2012 in Fujian and Jiangxi and the surrounding areas, its purpose is to verify the reliability of the three-dimensional nonlinear finite element model results established by the situation of crust classification in Fujian and Jiangxi.

5) The reliability and accuracy of earthquake monitoring capability of 24 observation sites in Fujian and Jiangxi will be evaluated and graded through integrating three-dimensional nonlinear finite element models and five earthquake instances

\begin{tabular}{|c|c|c|c|}
\hline $\begin{array}{l}\text { Level } \\
\text { measurement } \\
\text { data analysis of } \\
\text { Fujian and }\end{array}$ & $\begin{array}{l}\text { The design } \\
\text { and } \\
\text { processing of }\end{array}$ & $\begin{array}{l}\text { Calculation results of finite element method model } \\
\text { and the preliminary classification of level sites in } \\
\text { Fujian and Jiangxi }\end{array}$ & $\begin{array}{l}\text { Monitoring } \\
\text { capability } \\
\text { evaluation of }\end{array}$ \\
\hline & & & each level site in \\
\hline $\begin{array}{l}\text { cross-fault from } \\
2008 \text { to } 2012\end{array}$ & $\begin{array}{l}\text { element } \\
\text { method model }\end{array}$ & $\begin{array}{l}\text { Practical earthquake examples verifying the accuracy } \\
\text { of calculation results of the finite element method } \\
\text { model }\end{array}$ & $\begin{array}{c}\text { Fujian and } \\
\text { Jiangxi }\end{array}$ \\
\hline
\end{tabular}

Fig. 1 The technology roadmap

Model design ideas. By conducting a preliminary analysis of the situation of fault where 24 leveling observation sites locate, we can see that different factors for each observation site of fault have two kinds: fault strike and dip angle. Then through the observation of leveling data from 2008 to 2012, we will find that when the fault strike and dip angle change, there are some differences in earthquake reflecting ability of the same earthquake. Based on this characteristic of faults, by constantly changing the direction and angle of the fault, and then apply some pressure in the direction of the east side of the fault, by simulating the fault level change to analyze the stability and reliability of the monitoring capability of 24 observation sites.

Two models processing methods are set respectively according to the fault dip Angle and the fault strike:

1) When study the angle of impact on the cross-fault level monitoring capabilities, two times of 20mm displacement effect (where the fault direction must be perpendicular to the applied force) are applied to the east side of the direction of the model boundary. The first time of displacement is as loaded of a background field; the second time of displacement is to enhance the role of the stress field of the simulation stress field of in the background. And calculate the changing situation of fault displacement angle.

2) When study the fault strike of impact on the cross-fault level monitoring capabilities, two times of 20mm displacement effect are also applied to the east side of the direction of the model boundary. But displacement loading direction must constantly change so that the included angle between the direction of displacement loading and fault strike increases from $0^{\circ}$ to $90^{\circ}$, and the result is to calculate the change over to the fault displacement direction.

The calculated results of model. Fault displacement which is calculated with the change of Angle and strike is shown in the figure below:

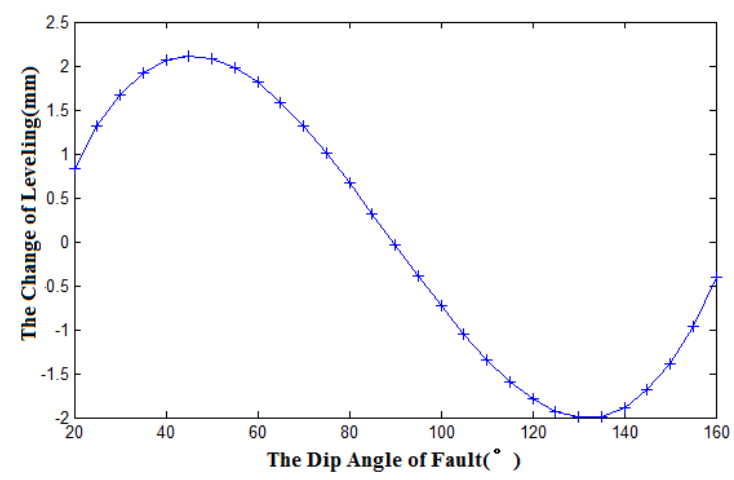

Fig. 2 Changes situation of fault displacement along with the dip angle 


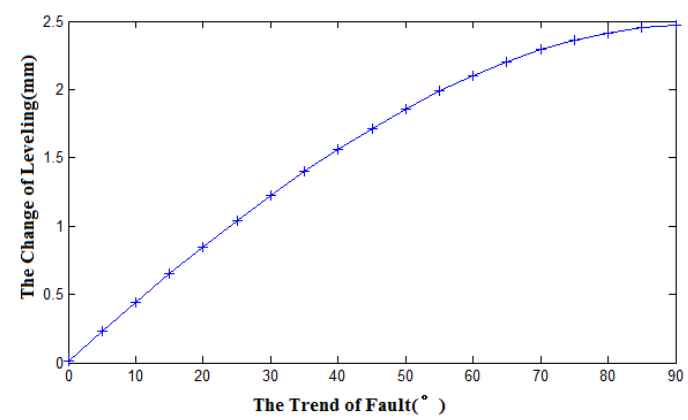

Fig. 3 Changes situation of fault displacement along with the fault strike

As can be seen from Figure 2, when the dip angle is different, the calculations of cross-fault level are quite different. When the fault dip is at $20^{\circ} \sim 160^{\circ}$, the relative vertical deformation amount of the fault measuring points on both sides are in sinusoidal shape. When the fault dip is at $40^{\circ} \sim 60^{\circ}$, the standard point will be most likely to capture the exception information and level change will be in maximum. But when the dip angle is below $20^{\circ}$ or $80^{\circ}$ above the fault, small variations are in the cross-fault level, especially when a fault angle is nearly vertical, the observing effect of level measuring point is the worst. When the dip angle is at $20^{\circ} \sim 40^{\circ}$ or $6^{\circ} \sim$ $80^{\circ}$, there will be small amplitude of changes in the level and the level will be able to receive a certain amount of abnormal information. When the dip angle is greater than $90^{\circ}$, it indicates faults tendency have changed, but the monitoring capability is the same as the variation characteristic of $20^{\circ} \sim 90^{\circ}$.

As can be seen from Figure 3, when the strike of the fault is not the same, the level of cross-fault values is also different. When fault strike fault is at $90^{\circ}$ and vertical to the horizontal ground, there will be a greater change in cross-fault level, which indicates when the fault strike is perpendicular to the horizontal ground, the measuring site on the fault can furthest capture the change of stress. But when the fault strike is close to $0^{\circ}$ that is parallel to the horizontal ground, the level point is almost impossible to capture the abnormal information brought about the stress.

\section{Theoretical classification and evaluation of monitoring capability in cross-fault level monitoring sites}

According to the calculation results of the above numerical simulation, the monitoring capabilities of cross-fault level monitoring sites in Fujian and Jiangxi can be divided into I, II,IIIthree levels which based on the extent of stress changes in the reflecting stress field. When the fault dip is at $40^{\circ} \sim 60^{\circ}$, changes of cross-fault level are the most significant which belongs to grade I sites. When the fault dip is at $20^{\circ} \sim 40^{\circ}$ and $60^{\circ} \sim 80^{\circ}$, changes of cross-fault level are significant which belongs to grade II sites. When the fault dip is below $20^{\circ}$ and at $80^{\circ} \sim 90^{\circ}$, changes of cross-fault level are not obvious which belongs to gradeIIIsites. At the same time, for different trending faults, when their horizontal angles with the ground are under $30^{\circ}$, the variation of cross-fault leveling is less than the most significant change in the relative magnitude of $1 / 2$, and its observations results are the most weakest for the reflecting capability of enhancing the boundary effect, and these can be classified as gradeIIIsites.

Because the Ring Dam site information is unknown, it can not be rated. Table 2 is based on the above ways to make a theoretical hierarchy result of 22 level observation sites in Fujian and Jiangxi.

Table 2 Theoretical classification of monitoring capability in cross-fault level monitoring sites in Fujian and Jiangxi

\begin{tabular}{cccc}
\hline Grade & I & II & III \\
\hline \multirow{3}{*}{ Station } & Sanshan, Shizishan, & Cannei, Liuxia, Meiling, Nanshan, Huangtian, & Putian, Dongzhang, \\
& Xitang, Qianlou, & Xiguazhou, Huzaishan, Rongqing, Xiexi, Guikou & Wangjian, Wankou, \\
& Dongdu, Yushan & & Kengnan, Hexi \\
\hline
\end{tabular}


The actual earthquake cases. Although Fujian and Jiangxi is one of the regions that occurred the new tectonic movement more frequently, but the frequency of occurrence of earthquakes is relatively small, and Taiwan which facing Fujian and Jiangxi provinces across the sea is earthquake-prone regions. Therefore, when judging the level monitoring capabilities of cross-faults in Fujian and Jiangxi, we should choose the actual situation of earthquakes in Taiwan Province to make a judgment. According to the data of China Earthquake Information Network, we selected three earthquakes of 5.5 magnitude in Taiwan and two earthquakes of 3.3 and 3.0 magnitude in Fujian and Jiangxi from 2008 to 2012. They are: an earthquake of 7 magnitude in Tainan, Kaohsiung County, Taiwan Province in March, 2008; an earthquake of 5.5 magnitude in Kaohsiung City, Taiwan Province in December, 2008; an earthquake of 6.7 magnitude in Pingtung County, Kaohsiung City, Taiwan Province in March, 2010; an earthquake of 3.0 magnitude in Shunchang County, Nanping City, Fujian and Jiangxi Provinces in May, 2012 and an earthquake of 3.3 magnitude in the near sea of Changle City, Fujian and Jiangxi Provinces in Sep, 2012.

Theoretical classification evaluation of earthquake monitoring sites. We have selected 4 monitoring sites which have already divided theoretically into I, II, IIIthree levels. The monitoring period of cross-fault in Fujian and Jiangxi is four months, but when fault activity is frequent, the time will be adjusted for two months.

Table 3 shows that when earthquakes happened, the level variation amount of cross-fault of grade I sites.

Table 3 Level variation of grade I sites /mm

\begin{tabular}{cccccc}
\hline \multirow{2}{*}{$\begin{array}{c}\text { serial number of } \\
\text { earthquake }\end{array}$} & $\begin{array}{c}\text { Earthquake of } \\
7.0 \text { magnitude } \\
\text { in Tainan }\end{array}$ & $\begin{array}{c}\text { Earthquake of } \\
5.5 \text { magnitude } \\
\text { in Gaoxiong }\end{array}$ & $\begin{array}{c}\text { Earthquake of } \\
6.7 \text { magnitude } \\
\text { in Pingdong }\end{array}$ & $\begin{array}{c}\text { Earthquake of } \\
3.0 \text { magnitude } \\
\text { in Nanping }\end{array}$ & $\begin{array}{c}\text { Earthquake of } \\
3.3 \text { magnitude } \\
\text { in Changle }\end{array}$ \\
\hline Qianlou & 7.42 & 2.89 & 0.44 & 0.69 & 0.96 \\
Sanshan & 0.22 & 0.75 & -0.82 & 2.07 & 1.65 \\
Yushan & - & -0.71 & 1.13 & -0.77 & -0.96 \\
Shizishan & - & 0.62 & -1.98 & -1.46 & 0.86
\end{tabular}

As can be seen from Table 3, four measuring sites had a more obvious level changes in five earthquakes. before and after the five earthquakes happened, change range of observation level was relatively large in Qianlou site, Sanshan site and Shizishan site had a slight weakness in monitoring capability of Taiwan province compared with the two earthquakes in Fujian and Jiangxi. But when we compared four data of Yushan, we could find that its seismic response was general and had a certain level of change, but the amplitude was smaller. Integrating the level changes of 4 sites, we could see that the monitoring ability of grade I observation sites was stronger and stable.

Table 4 shows that when earthquakes happened, the level variation amount of cross-fault of grade II sites.

Table 4 Level variation of grade I sites $/ \mathbf{m m}$

\begin{tabular}{cccccc}
\hline \multirow{2}{*}{$\begin{array}{c}\text { serial number of } \\
\text { earthquake }\end{array}$} & $\begin{array}{c}\text { Earthquake of } \\
7.0 \text { magnitude } \\
\text { in Tainan }\end{array}$ & $\begin{array}{c}\text { Earthquake of } \\
5.5 \text { magnitude } \\
\text { in Gaoxiong }\end{array}$ & $\begin{array}{c}\text { Earthquake of } \\
6.7 \text { magnitude } \\
\text { in Pingdong }\end{array}$ & $\begin{array}{c}\text { Earthquake of } \\
3.0 \text { magnitude } \\
\text { in Nanping }\end{array}$ & $\begin{array}{c}\text { Earthquake of } \\
3.3 \text { magnitude } \\
\text { in Changle }\end{array}$ \\
\hline Liuxia & - & 3.32 & 1.21 & -1.97 & 0.16 \\
Guikou & - & 1.02 & -0.79 & 0.93 & 0.08 \\
Xiexi & -4.5 & 4.19 & 2.19 & -3.48 & -1.7 \\
Canei & - & -2.08 & -2.95 & 4.17 & -0.32 \\
\hline
\end{tabular}

As can be seen from Table 4, the 4 sites of Liuxia, Guikou, Xiexi and Cannei was not worse than the 4 sites of grade I in level reaction of the 5 earthquakes, but the 3 sites of Liuxia, Guikou and Cannei had a poor reaction to the earthquake of 3.3 magnitude in Changle. Above these show that these sites have good monitoring capabilities, but they are lack of monitoring 
stability, when they monitor earthquakes, they have a slow response to seismic information in some areas.

Table 5 shows that when earthquakes happened, the level variation amount of cross-fault of gradeIIIsites.

Table 5 Level variation of gradeIIIsites / $/ \mathbf{m m}$

\begin{tabular}{cccccc}
\hline \multirow{2}{*}{$\begin{array}{c}\text { serial number of } \\
\text { earthquake }\end{array}$} & $\begin{array}{c}\text { Earthquake of } \\
7.0 \text { magnitude } \\
\text { in Tainan }\end{array}$ & $\begin{array}{c}\text { Earthquake of } \\
5.5 \text { magnitude } \\
\text { in Gaoxiong }\end{array}$ & $\begin{array}{c}\text { Earthquake of } \\
6.7 \text { magnitude } \\
\text { in Pingdong }\end{array}$ & $\begin{array}{c}\text { Earthquake of } \\
3.0 \text { magnitude } \\
\text { in Nanping }\end{array}$ & $\begin{array}{c}\text { Earthquake of } \\
3.3 \text { magnitude } \\
\text { in Changle }\end{array}$ \\
\hline Wangjian & - & 2.78 & 0.22 & -0.795 & 0.22 \\
Putian & - & 1.05 & -0.04 & -0.35 & -0.2 \\
Wankou & 0.83 & 2.11 & -0.56 & 0.98 & 1.32 \\
Hexi & 0.86 & 0.25 & 0.06 & 0.08 & 0.74
\end{tabular}

As can be seen from Table 5, the 3 sites of Wangjian, Putian and Hexi had a poor sensitivity of the five earthquakes in Fujian, Jiangxi and nearby areas. When the five earthquakes happened, the level variation amount was small and seismic monitoring capabilities were inadequate. But Wangkou site had a strong earthquake reflecting ability and there was an obvious level change in each earthquake.

In summary, the monitoring capability of grade I sites is stronger and relatively stable, the monitoring capability of grade II sites is stronger but poor stability, grade III sites have a certain degree of monitoring capability of earthquakes in some areas but their overall monitoring capability is poor.

Table 6 Level sites classification of cross-faults in Fujian and Jiangxi

\begin{tabular}{|c|c|c|c|c|c|c|}
\hline Number & Observing names & $\begin{array}{l}\text { Simulative } \\
\text { classification }\end{array}$ & $\begin{array}{l}\text { Monitoring } \\
\text { capability }\end{array}$ & Stability & $\begin{array}{c}\text { Final } \\
\text { classification }\end{array}$ & $\begin{array}{l}\text { Whether to } \\
\text { modify or not }\end{array}$ \\
\hline 1 & Cannei town in Anxi county & II & strong & strong & I & Yes \\
\hline 2 & Dongzhang town in Fuqing city. & III & weak & - & III & \\
\hline 3 & Guikou villiage in Yongan city & II & strong & weak & II & \\
\hline 4 & Hexi town in Nanjing county & III & weak & - & III & \\
\hline 5 & Nankeng village in Minhou county & III & weak & - & III & \\
\hline 6 & Liuxia village in Zhangpu county & II & strong & weak & II & \\
\hline 7 & Meiling village in Huian county & II & strong & weak & II & \\
\hline 8 & Nanshan village in Pinghe county & II & strong & weak & II & \\
\hline 9 & Putian city & III & weak & weak & III & \\
\hline 10 & Qianlou town in Dongshan county & $\mathrm{I}$ & strong & strong & I & \\
\hline 11 & Rongqing in Shishi city & II & strong & weak & II & \\
\hline 12 & Sanshan town in Fuqing & I & strong & weak & II & Yes \\
\hline 13 & Shizishan in Taining county & I & strong & strong & I & \\
\hline 14 & Wangjian village in Datian county & III & strong & weak & II & Yes \\
\hline 15 & Yushan town in Jianou county & I & strong & strong & I & \\
\hline 16 & Xiexi & II & strong & weak & II & \\
\hline 17 & Huangtian & II & strong & weak & II & \\
\hline 18 & Wankou & III & strong & strong & I & Yes \\
\hline 19 & Xiguazhou & II & weak & - & III & Yes \\
\hline 20 & Xitang & - & weak & - & III & \\
\hline 21 & Dongdu & I & strong & strong & I & \\
\hline 22 & Dabeihuan & - & strong & strong & I & \\
\hline
\end{tabular}




\begin{tabular}{cccccc}
\hline 23 & Huzaishan & II & strong & weak & II \\
24 & Xiefang & & & & \\
\hline
\end{tabular}

The classification of seismic monitoring. According to the simulation results of the finite element method, according to the earthquake reflecting ability and stability for five actual earthquakes, we will make a classification adjustment of 24 sites in Fujian and Jiangxi, among them there are 16 sites the same as simulation classification and 5 different.

By comparing the model dealing results with the predicting results of earthquake cases, we will find: conclusions of finite element model and conclusions of actual earthquakes are basically the same, because of other factors (such as geographic location, fault altitude, etc.) of several sites' influence, we need to adjust the evaluation of site monitoring ability, and the results calculated by the finite element model also has a certain reference significance. For the 24 sites of Fujian and Jiangxi, on the whole they have a strong monitoring ability to capture the certain information when the faults suffer stress change.

\section{Conclusion}

Based on the actual crust of Fujian and Jiangxi, this paper established three-dimensional finite element model, the cross-fault level changes at different inclination and direction can be calculated by ANSYS three-dimensional finite element software. This paper also take advantage of the five earthquake instances to demonstrate the reliability of three-dimensional finite element model. Finally, it synthesize the model results and the actual earthquake results to make a preliminary classification evaluation of 24 level observation sites in Fujian and Jiangxi. The results show below:

1) There are 24 level observation sites in Fujian and Jiangxi which include 8 grade I sites, 10 grade II sites and 6 gradeIIIsites. On the whole, sites have a strong monitoring capability.

2) Conclusions of finite element model and actual earthquakes are basically the same, at the time of rating the sites, we should consider synthetically the factors of inclination angle and direction and other aspects of the factors such as measurement position.

3) When the inclination is close to $60^{\circ}$ and the fault strike is perpendicular to the horizontal ground, the monitoring capability of the site is stronger.

4) When the inclination is close $0^{\circ}$ and $90^{\circ}$ and the fault strike is parallel to the horizontal ground, the monitoring capability of the site is weaker.

\section{Acknowledgements}

Funded projects: Scientific research fund project of Seismological Bureau of Fujian Province (No. FS201411) and Scientific research fund project of Fujian Province (No.2016J01199).

\section{References}

[1] Ding XH, Wang YD and Ye SJ(1999), Active Fault and Earthquake of Southeast Coast in Fujian , Fujian science and Technology Press, Fujian. (in Chinese)

[2] Huang QT, Ding XH and Zhuang JY(1999), "The Formation and Development of Late Quaternary Fault Tectonic of Southeastern Coastal in Fujian Province," Seismological Press, Beijing, pp.67-80. (in Chinese)

[3] Bo WJ, Yang GH and Guo QL(2001), Research on Crustal Deformation and Earthquake Prediction, Seismological Press, Beijing. (in Chinese)

[4] Bo WJ and Guo QL(2000),"The Comprehensive Research of Geological Structure and Geodetic Deformation," The Eurasian Economic Press,HongKong, pp.13-22. (in Chinese)

[5] Zhang HY, Xie FR, Jiao Q and Li RS(2007), " Cross-fault Deformation Observation and Crustal Stress Field in Capital Circle Region," Seismology and Geology, 29(4):706-714. (in Chinese)

[6] Chen QF and Deng DL(2002), Earthquake Cases in China(1995-1996) , Seismological Press, Beijing. (in Chinese) 
[7] Su Q, Yang YL and Xiang HP(2012), "Seismicity Character Analysis on the Xianshuihe Faults Before and After the 2008 Wenchuan M8.0 Earthquake," Earthquake Research in Sichuan, (1):24-29. (in Chinese)

[8] Han ZJ and Guo SM(2004), " Seismotectonic environment of occurring the February 3,1996 Lijiang M=7.0 earthquake, Yunnan Province," Acta Seismologica Sinica, 17(4):453-463. 